\title{
PENINGKATAN PEMAHAMAN KONSEP FISIKA DAN AKTIVITAS MAHASISWA MELALUI PhET SIMULATION
}

\author{
Elisa $^{1)}$, Ainun Mardiyah ${ }^{1)}$, Rizky Ariaji ${ }^{2)}$ \\ ${ }^{1)}$ Pendidikan Fisika, FKIP Universitas Muhammadiyah Tapanuli Selatan \\ ${ }^{2)}$ Pendidikan Kimia, FKIP Universitas Muhammadiyah Tapanuli Selatan \\ elisa@um-tapsel.ac.id,
}

\begin{abstract}
Understanding the concept as one of the keys to success in studying science especially Physics, so do not have to memorize the formula but enough just by understanding the concept alone. Based on observations during community research activities, some positive results were obtained: Participants showed very high attention to the material using PhET Simulation. From the preliminary test in cycle I the pretest score of about $10 \%$ is able to answer to $77.5 \%$, while in cycle II the value of the dropper about $20 \%$ increased to $97.5 \%$. While for the activity of students which cover the realm of ability to use PhET Simulation from $73,75 \%$ in cycle I increase to $85 \%$ in cycle II, In enthusiasm Attitude enthusiasm using PhET Simulation from $75 \%$ in cycle I increased to $86,25 \%$ in cycle II, In the field of cooperation in the group using PhET Simulation of $72.5 \%$ in the first cycle increased to $86.25 \%$ in cycle II. In the realm of the ability to use worksheets in PhET Simulation from $75 \%$ in cycle I increased to $88.75 \%$ in cycle II. In the sphere of participation in the discussion using PhET Simulation from $75 \%$ in the first cycle increased to $86.25 \%$ in cycle II. The result of the research is the increasing of concept comprehension and the increasing of student learning activity.
\end{abstract}

Keywords: PhET Simulation, Conceptual Understanding, Learning Activities.

\begin{abstract}
Abstrak
Pemahaman konsep sebagai salah satu kunci keberhasilan dalam mempelajari sains khususnya Fisika, sehingga tidak harus menghapal rumus tetapi cukup hanya dengan memahami konsepnya saja. Berdasarkan pengamatan selama kegiatan penelitian masyarakat, diperoleh beberapa hasil yang positif diantaranya adalah: Para peserta menunjukkan perhatian yang sangat tinggi terhadap materi dengan menggunakan PhET Simulation. Dari Tes awal pada siklus I nilai pretes dari sekitar $10 \%$ yang mampu menjawab menjadi $77,5 \%$, sedangkan pada siklus II nilai pretes dari sekitar $20 \%$ meningkat menjadi $97,5 \%$. Sedangkan untuk aktivitas mahasiswa meliputi ranah kemampuan menggunakan PhET Simulation dari $73 \%$ pada siklus I meningkat menjasi $85 \%$ pada siklus II. Pada ranah Sikap antusias menggunakan PhET Simulation dari $75 \%$ pada siklus I meningkat menjadi $86,25 \%$ pada siklus II. Pada ranah kerjasama dalam kelompok mengunakan PhET Simulation dari 72,5\% pada siklus I meningkat menjadi $86,25 \%$ pada siklus II. Pada ranah kemampuan menggunakan lembar kerja PhET Simulation dari $75 \%$ pada siklus I meningkat menjadi $88,75 \%$ pada siklus II. Pada ranah partisipasi dalam siskusi mengunakan PhET Simulation dari $75 \%$ pada siklus I meningkat menjadi $86,25 \%$ pada siklus II. Hasil dari penelitian adalah bertambahnya pemahan konsep dan meningkatnya aktivitas belajar mahasiswa.
\end{abstract}

Kata Kunci: PhET Simulation,Pemahaman konsep, Aktivitas belajar. 


\section{PENDAHULUAN}

Salah satu tujuan pendidikan adalah memfasilitasi mahasiswa mencapai pemahaman yang dapat diungkapkan secara lisan, berupa angka dan kerangka berpikir yang positif (Dahar, 1988). Pemahaman dapat diabstraksikan sebagai landasan untuk memperoleh kemampuan pemecahan masalah, berpikir kreatif dan kritis, dan pengambilan keputusan. Oleh karena itu, pembelajaran untuk pemahaman merupakan pembelajaran untuk berpikir tingkat tinggi.

Pemahaman konsep adalah proses perbuatan untuk mengerti benar tentang suatu rancangan atau suatu ide abstrak yang memungkinkan seseorang untuk menggolongkan suatu objek atau kejadian, dan pemahaman konsep diperoleh melalui proses belajar. Pemahaman merupakan hasil belajar mengajar yang mempunyai indikator dan setiap individu dapat menjelaskan atau mendefenisikan suatu bagian informasi dengan kata-kata sendiri.

Dalam taksonomi bloom, kesanggupan memahami setingkat lebih tinggi daripada mengingat. Banyak penyebab yang melatar belakangi pemahaman konsep Fisika masih rendah, diantaranya pembelajaran yang masih menggunakan metode tradsional (Gok \& Silay, 2008) dan tidak kontekstual (Wahyudi, 2006). Disamping itu, guru Fisika belum efektif melatih kemampuan pemahaman konsep sehingga siswa kurang bahkan tidak memiliki kemampuan pemahaman konsep (Brok dkk.,2010). Siswa menggunakan pendekatan plug and chug dan memory-based dalam memecahkan soal-soal Fisika (Walsh, 2007). Selain itu berdasarkan observasi di lapangan, hampir sebagian besar mahasiswa yang mempelajari mata kuliah Fisika Dasar I kurang memahami konsep, akibatnya keterampilan berpikir kritis mereka juga kurang. Aktivitas pembelajaran hanya mengacu pada pembelajaran langsung atau konvensional.
Eksperimen yang seharusnya dilakukan di laboratorium sebagai tempat untuk mengaplikasikan teori keilmuan, pengujian teoritis, pembuktian uji coba, penelitian dan sebagainya dengan menggunakan alat bantu yang menjadi kelengkapan dari fasilitas dengan kuantitas dan kualitas yang memadai (Depdiknas, 2002) sepertinya hanya menjadi anganangan semata. Hal ini tidak hanya dikarenakan peralatan laboratorium yang minim, tetapi juga keterbatasan modul praktikum yang diberikan. Sehingga berakibat kepada nilai mata kuliah Fisika Dasar dan Praktikum Fisika Dasar. Pada tahun 2015, nilai rata-rata pretes untuk hukum Newton pada matakuliah Fisika Dasar adalah 52,34 dan nilai rata - rata pretes untuk hukum Newton pada matakuliah praktikum Fisika Dasar adalah 46,72. Setelah dilakukan wawancara langsung dengan mahasiswa, maka didapatlah beberapa kesimpulan bahwa pemahaman konsep mahasiswa tentang materi hukum Newton masih kurang.

Penyebabnya adalah mahasiswa tidak mengerti mengenai konsep dari hukum Newton sehingga ketika diberikan soal mengenai konsep, mereka sedikit bingung. Mereka hanya mampu mengerjakan soal mengenai hitungan dan bukan konsep. Padahal untuk menjadi pendidik Fisika, tidak hanya mampu berhitung, juga harus mampu menguasai konsep. Oleh karena itu diperlukan suatu pembelajaran yang tidak hanya mampu menguasai konsep saja tetapi juga mampu menyesuaikannya dengan praktek.

Salah satu upaya untuk mengatasi ketidaksempurnaan pembelajaran Fisika adalah melalui pemanfaatan teknologi dan informasi dan komputer. Finkelstein (2005) mengatakan bahwa komputer dapat digunakan untuk menunjang pelaksanaan praktikum Fisika, baik untukmemahami konsep, mengumpulkan data, menyajikan dan mengolah data. Selain itu, komputer juga dapat digunakan untuk memodifikasi eksperimen dan menampilkan eksperimen lengkap dalam bentuk virtual yang disebut 
Virtual Laboratory Model (VLM ). Virtual Laboratory model merupakan objek multimedia interaktif yang kompleks dan termasuk bentuk digital baru, dengan tujuan pembelajaran implisit atau eksplisit (Budhu, 2002).

$$
\text { Penerapan laboratorium maya }
$$
dalam pembelajaran dapat dilatihkan pemahaman konsep, kemampuan berpikir, Science process skills, Communication skill, ICT skills dan interperation skills. Salah satu VLM yang berkembang pesat pada saat ini khususnya pada pembelajaran Fisika adalah "PhET Simulation Interactive" yang dikembangkan oleh Universitas Colorado di Amerika Serikat. Melalui PhET (Physics Education Technology) Simulation Interactive dapat memberikan banyak kebebasan bagi mahasiswa untuk memahami konsep, aktivitas, berpikir kritis dan kreatif, karena kita dapat mensikronisasikan antara laboratorium maya dengan real laboratory.

Berdasarkan masalah diatas, Penulis memberikan solusi dalam menyelesaikan permasalahan tersebut dengan menggunakan PhET Simulation Interactive untuk meningkatkan pemahaman konsep mahasiswa.

\section{METODE}

Berdasarkan permasalahan yang telah di kemukakan, maka dalam kegiatan penelitian ini metode pelaksanaan yang digunakan adalah metode pelaksanaan menggunakan penelitian tindakan kelas yang terdiri atas 2 siklus terhadap mahasiswa pendidikan Fisika UMTS.

\section{HASIL DAN PEMBAHASAN}

Kemampuan mahasiswa memahami konsep fluida bergerak dan vektor mengalami peningkatan dari hasil postes pada siklus I dan siklus II.
Tabel 1: Hasil pemahaman konsep mahasiswa

\begin{tabular}{|c|c|c|c|c|}
\hline Pencapaian & \multicolumn{2}{|c|}{ Siklus I } & \multicolumn{2}{|c|}{ Siklus II } \\
\hline $\begin{array}{l}\text { Hasil } \\
\text { Belajar }\end{array}$ & $\begin{array}{l}\text { Pre } \\
\text { tes }\end{array}$ & $\begin{array}{l}\text { Post } \\
\text { tes }\end{array}$ & $\begin{array}{l}\text { Pre } \\
\text { tes }\end{array}$ & $\begin{array}{l}\text { Post } \\
\text { tes }\end{array}$ \\
\hline $\begin{array}{l}\text { Nilai Rata- } \\
\text { rata }\end{array}$ & 42,33 & 64,84 & 47,83 & 70,33 \\
\hline $\begin{array}{l}\text { Standar } \\
\text { Deviasi }\end{array}$ & 9,49 & 9,89 & 11,15 & 6,14 \\
\hline Nilai & 4 & 31 & 8 & 39 \\
\hline $\begin{array}{l}\text { Persentasi } \\
\text { Ketuntasan }\end{array}$ & $10 \%$ & $77,50 \%$ & $20 \%$ & $97,50 \%$ \\
\hline
\end{tabular}

Setelah diadakan penilaian, terjadi peningkatan hasil belajar mahasiswa pada setiap siklusnya dengan standar deviasi dari siklus I ke siklus II semakin kecil artinya sebaran nilai mahasiswa semakin kecil. Mahasiswa yang pengetahuan kognitifnya baik terus mengalami peningkatan sementara ada beberapa Mahasiswa yang kemampuan kognitifnya masih kurang perlu ditingkatkan agar tidak tertinggal jauh. Selain itu aktivitas mahasiswa pada proses pembelajaran secara kumulatif keterlibatan mahasiswa dalam proses pembelajaran konsep fluida bergerak dan vektor dapat dilihat pada gambar berikut:

Tabel 2: Hasil Aktivitas mahasiswa pada siklus I

\begin{tabular}{lcc}
\hline \multicolumn{1}{c}{$\begin{array}{c}\text { Aspek yang } \\
\text { Diamati }\end{array}$} & $\begin{array}{c}\text { Skor } \\
\text { Perolehan }\end{array}$ & Persentase \\
\hline $\begin{array}{l}\text { Kemampuan } \\
\text { menggunakan }\end{array}$ & 118 & $73,75 \%$ \\
$\begin{array}{l}\text { PhET Simulation } \\
\text { Sikap Antusias }\end{array}$ & 120 & $75,00 \%$ \\
$\begin{array}{l}\text { Kerjasama dalam } \\
\text { kelompok }\end{array}$ & 116 & $72,50 \%$ \\
$\begin{array}{l}\text { Kemampuan } \\
\text { dalam menjawab }\end{array}$ & 120 & $75,00 \%$ \\
$\begin{array}{l}\text { lembar kerja } \\
\text { Partisipasi dalam } \\
\text { diskusi }\end{array}$ & 120 & $75,00 \%$ \\
\hline
\end{tabular}

Pembelajaran dengan menggunakan PhET Simulation sederhana diskusi dan presentasi ternyata tidak semua mahasiswa yang berperan aktif masih ada mahasiswa yang hanya mengandalkan mahasiswa yang 
lebih pintar pada diskusi dan presentasi hasil percobaan. Hal ini disebabkan suasana proses pembelajaran yang berbeda dari biasanya dari mendengar informasi, mencatat, dan terpusat pada dosen menjadi mahasiswa yang berperan aktif.

$$
\text { Dengan adanya sebagian }
$$

mahasiswa mengalami kesulitan memahami persamaan kontinuitas maka dosen perlu membimbing mahasiswa lebih optimal cara menggunakan PhET Simulation sehingga mengurangi tingkat kesalahan dan menjelaskan cara mengamati proses atau peristiwa yang terjadi. Selama kegitan pembelajaran dengan menggunakan PhET Simulation berlangsung dosen harus secara aktif memantau kegiatan belajar mahasiswa sehingga memahami kesulitan-kesulitan mahasiswa dalam membuat catatan hasil pengamatan.

Partisipasi dalam kegiatan kelompok masih perlu ditingkatkan, kegiatan kelompok hanya didominasi oleh mahasiswa tertentu saja dalam menyelesaikan permasalahan. Pada kegiatan persentase dalam siklus ini hanya sebagian kecil mahasiswa yang berperan aktif dalam bertanya dan menjawab pertanyaan.

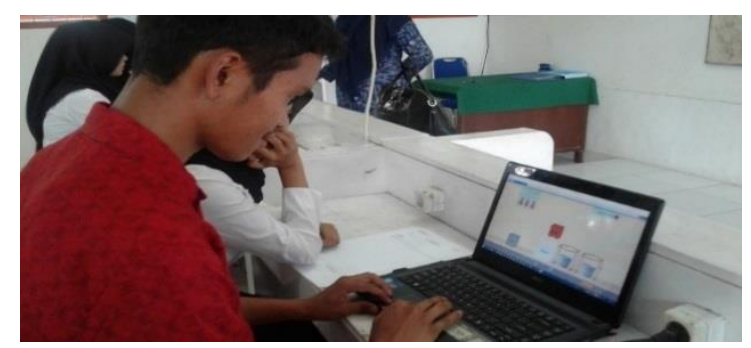

Gambar 1: Kegiatan mahasiswa pada siklus I

Dari refleksi diakhir siklus I, maka dilakukan perbaikan untuk siklus II yaitu: Agar lebih meningkatkan keterlibatan mahasiswa maka jumlah anggota dalam setiap kelompok dikurangi. Dari delapan kelompok dijadikan menjadi 10 kelompok dimana setiap kelompoknya terdiri dari 4 mahasiswa, setiap anggota kelompok diberi tugas tertentu pada saat menggunakan PhET Simulation. Dosen melakukan pemeriksaan terhadap hasil percobaan pada masing-masing lembar kegiatan mahasiswa, Membimbing mahasiswa agar aktif bertanya baik kepada dosen ataupun teman dalam satu kelompok maupun kelompok lain.

Tabel 3: Hasil Aktivitas mahasiswa pada siklus II

\begin{tabular}{lcc}
\hline \multicolumn{1}{c}{$\begin{array}{c}\text { Aspek yang } \\
\text { Diamati }\end{array}$} & $\begin{array}{c}\text { Skor } \\
\text { Perolehan }\end{array}$ & Persentase \\
\hline $\begin{array}{l}\text { Kemampuan } \\
\text { menggunakan }\end{array}$ & 136 & $85,00 \%$ \\
$\begin{array}{l}\text { PhET Simulation } \\
\text { Sikap Antusias }\end{array}$ & 138 & $86,25 \%$ \\
$\begin{array}{l}\text { Kerjasama dalam } \\
\text { kelompok }\end{array}$ & 138 & $86,25 \%$ \\
$\begin{array}{l}\text { Kemampuan } \\
\text { dalam menjawab }\end{array}$ & 142 & $88,75 \%$ \\
$\begin{array}{l}\text { lembar kerja } \\
\text { Partisipasi dalam } \\
\text { diskusi }\end{array}$ & 138 & $86,25 \%$ \\
\hline
\end{tabular}

Proses pembelajaran pada siklus II tentang azas Bernaulli, persamaan Bernaulli dan penerapan hukum Bernaulli dengan menggunakan PhET Simulation yang dibuat sebelum proses belajarmengajar berlangsung, jumlah kelompok mahasiswa dari 8 kelompok menjadi 10 kelompok hal ini berdampak suasana kelas menjadi semangkin kondusif. Dosen selalu memberikan kesempatan pada mahasiswa seluas-luasnya untuk bertanya jika ada yang masih belum paham dan mengerti tentang materi yang dipelajari. Tes hasil belajar mahasiswa mencapai rata-rata nilai 70,33 dan mahasiswa yang tuntas belajar mencapai $97,50 \%$ dari 40 mahasiswa. Mahasiswa yang mencapai ketuntasan belajar 39 mahasiswa.

Keterlibatan mahasiswa pada proses pembelajaran dengan menggunakan PhET Simulation berlangsung amat sangat baik bahkan interaksi dalam kelompok maupun dengan dosen juga baik. Dalam diskusi dan presentasi mengenai hasil pengamatan terhadap peragaan yang dilakukan sudah 
tidak mengalami keseulitan, mahasiswa yang mengajukan pertanyaan maupun yang menjawab pertanyaan baik dari temannya maupun dari dosen sudah meningkat.

Sikap mahasiswa mendapat respon yang baik dari Mahasiswa. Dari 40 mahasiswa sebanyak $82,50 \%$ menyatakan sangat setuju bahwa penggunaan alat peraga dalam proses pembelajaran konsep fluida bergerak adalah sangat menarik, mudah, menyenangkan dan sangat setuju untuk dilanjutkan. Adapun sebanyak $17,50 \%$ mahasiswa menyatakan setuju dan tidak ada seorangpun mahasiswa yang menyatakan tidak tahu, tidak setuju, apalagi sangat tidak setuju.

Pendapat mahasiswa terhadap Penggunaan PhET Simulation pada Proses Pembelajaran. Dari hasil wawancara dengan Mahasiswa pada akhir siklus II bahwa proses pembelajaran dengan menggunakan PhET Simulation Mahasiswa merasa lebih rileks, menarik, tidak membosankan, dan lebih mudah untuk dipahami.

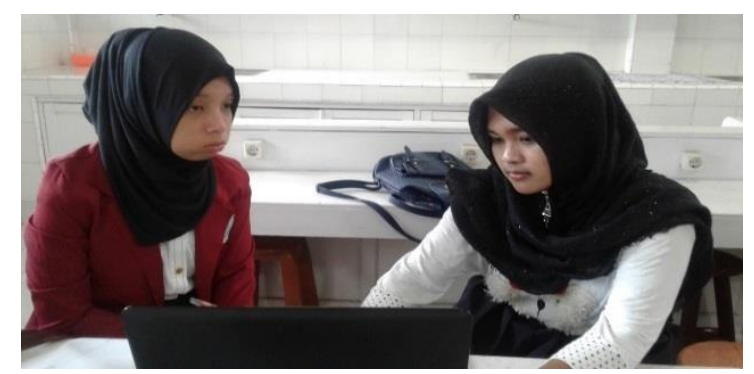

Gambar 2: Kegiatan diskusi mahasiswa menjawab lembar pengamatan

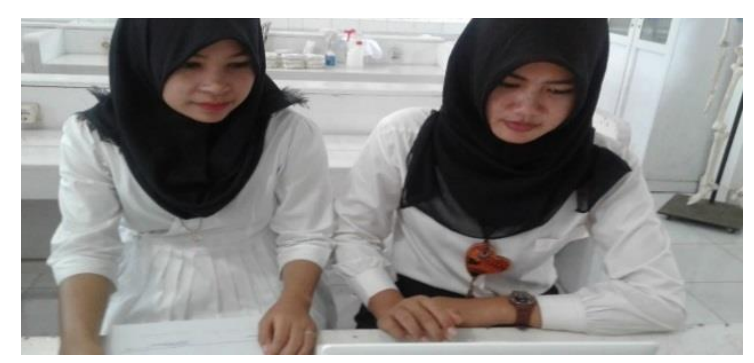

Gambar 3: Kegiatan pengisian lembar pengamatan menggunakan PhET Simulation

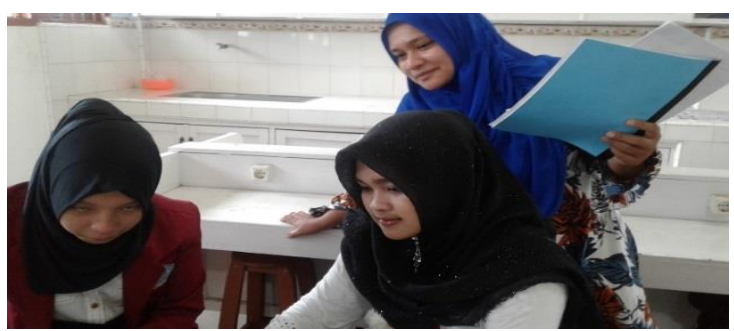

Gambar 4: Kegiatan diskusi dengan dosen pembimbing

Dari hasil pengamatan dan hasil tes hasil belajar pada siklus II : Penggunaan PhET Simulation memberikan pengaruh yang positif terhadap proses pembelajaran konsep fluida bergerak dan vektor karena proses pembelajaran ini lebih menarik, menyenangkan, rileks, tidak membosankan mahasiswa, dan yang paling penting mahasiswa belajar tanpa ada rasa terbebani oleh konsep-konsep yang sulit sehingga meningkatkan hasil belajarnya, Secara kualitatif susana pembelajaran dirasakan lebih kondusif dibandingkan sebelum dilakukan tindakan terutama terlihat pada terciptanya kerja sama antara mahasiswa dengan mahasiswa dalam kelompok dan mahasiswa.

Dengan meningkatnya keterlibatan mahasiswa pada proses belajar mengajar dalam setiap siklus dan terciptanya pembelajaran yang aktif, kreatif, inovatif dan menyenangkan ini, maka meningkatkan pula nilai rata-rata mahasiswa sehingga pembelajaran lebih efektif.

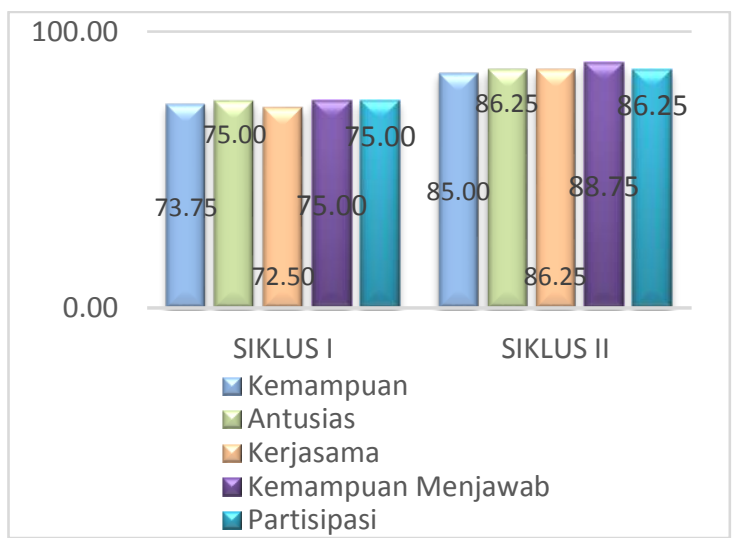

Gambar 5: Peningkatan aktivitas mahasiswa pada siklus I dan II 
Elisa, dkk. Peningkatan Pemahaman Konsep Fisika Dan Aktivitas...

\section{SIMPULAN}

Berdasarkan hasil dan pembahasan penelitian tindakan kelas yang dilakukan dengan menggunakan PhET simulation dapat ditarik kesimpulan sebagai berikut: (1) Penggunaan PhET simulation pada proses pembelajaran konsep fluida bergerak dapat meningkatkan hasil belajar mahasiswa. (2) Pengunaan PhET simulation pada proses pembelajaran konsep fluida bergerak dapat meningkatkan aktivitas mahasiswa.

\section{UCAPAN TERIMA KASIH}

Terima kasih kepada Universitas Muhammadiyah Tapanuli Selatan yang telah memberikan Dana Penelitian tahun anggaran 2016. APB Universitas Muhammadiyah Tapanuli Selatan (UMTS)

\section{DAFTAR PUSTAKA}

Budhu, M. (2002). Virtual Laboratories for Engineering Education. Paper Presented at international conference of engineering Education. Manchester, U. K. Agustus, $\mathrm{p}$.

Brok, P. D., Taconis, R. dan Fisher, D. (2010). How well do Science Teacher Do?Differences in teacherstudent interpersonal behavior between Science Teachers and teachers of other (school) Subjects. The open education Journal,3.
Depdiknas, (2002), SPTK-21, Jakarta.

Dahar, Ratna Wilis, DR. (1988). Teori Teori Belajar. Departemen Pendidikan dan Kebudayaan Direktorat jenderal Pendidikan Tinggi. Jakarta.

Finkelstein, et. al. (2005). When Learning About the real World is better done Virtually ; A study of substituting Computer Simulations for Laboratory Equipment". Physics Education Research. APS (1).

Gok, T. \& Silay.,I.. (2008). Effect of Problem Solving Strategy Teaching on the problem solving attitude of cooperative learning group. Journal of Theory and practice in education. $4(2)$.

Wahyudi. (2006). Upaya peningkatan prestasi belajar Fisika dengan memvisualkan konsep Fisika dalam kehidupan nyata sehari-hari. Jurnal Dinamika pendidikan.

Walsh, L. N., Howard, R. G..\& Bowe, B.. (2007). Phenomegraphy Study of Students Problem Solving Approach in Physics. Physics Education Reasearch (online). 3 (2). 